\title{
HOC VOLVMINE CONTINENTVR
}

Praefatio

Librorum conspectus

LXII

Conspectus siglorum in apparatu laudatorum LXVII

I. Severi Alexandrini narrationes.................................................. 1

1. Narratio de viola..................................................................... 3

2. Narratio de Hyacintho .......................................................4

3. Narratio de Narcisso ............................................................. 5

4. Narratio de Arione .............................................................6

5. Narratio de Icaro ...................................................................

6. Narratio de Oto et Ephialte .............................................. 8

II. Severi Alexandrini ethopoeiae ...............................................9

1. Briseidis ethopoeia .............................................................. 11

2. Achillis ethopoeia .......................................................... 12

3. Menelai ethopoeia.......................................................... 13

4. Hectoris ethopoeia.......................................................... 15

5. Herculis ethopoeia............................................................ 17

6. Aeschinis ethopoeia ......................................................21

7. Aeschinis ethopoeia .......................................................23

8. Demosthenis ethopoeia ..................................................25

9. Pictoris ethopoeia .........................................................26

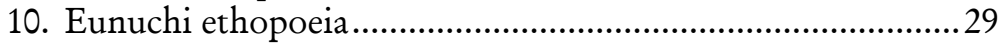

III. Callinici sophistae testimonia et fragmenta ............................. 31

IV. Adriani Tyrii sophistae testimonia et fragmenta .....................47

V. Anonymi ethopoeia meretricis redemptae .............................77

Index nominum et ethnicorum a Severo laudatorum ....................88 
Index Severi Graecitatis .... 88

Severi editionum congruentiae 130

Callinici editionum congruentiae. 132

Addendum 134 